\title{
AKTIVITAS FISIK, KONSUMSI MAKANAN CEPAT SAJI DAN KOMPOSISI LEMAK TUBUH REMAJA SMA KARUNA DIPA PALU
}

\author{
Physical Activity, Consumption of Fast Foods and Body Fat Composition of \\ SMA Karuna Dipa Palu's Adolescents
}

\author{
Fahmi Hafid $^{1}$, Yayuk Eka Cahyani ${ }^{2}$, Ansar $^{3}$ \\ Poltekkes Kemenkes Palu \\ Email: hafid.fahmi79@gmail.com
}

\begin{abstract}
ABSTRAK
Kelebihan berat badan (overweight) dan obesitas pada remaja merupakan faktor risiko penyakit diabetes, kardiovaskular, dan kanker. Hal ini disebabkan karena terjadinya penimbunan lemak pada jaringan adiposa. Penelitian ini bertujuan untuk mengetahui hubungan aktivitas fisik dan konsumsi makanan cepat saji (fast foods) dengan komposisi lemak tubuh pada remaja di SMA Karuna Dipa Palu. Jenis penelitian ini adalah penelitian analitik dengan menggunakan pendekatan cross sectional. Sampel penelitian berjumlah 74 orang yang diambil menggunakan teknik systematic random sampling. Data komposisi lemak tubuh diketahui melalui pengukuran menggunakan alat BIA (Bioelectrical Impedance Analysis) merk KERN, data aktivitas fisik didapatkan melalui pengisian kuesioner aktivitas fisik selama seminggu terakhir, dan data konsumsi makanan cepat saji (fast foods) sebulan terakhir didapatkan melalui pengisian formulir FFQ (Food Frequency Questionnaire). Analisis data menggunakan uji chi square dengan nilai $\alpha=0,05$. Hasil penelitian menunjukkan $29,7 \%$ remaja memiliki komposisi lemak tubuh yang tinggi. Persentase remaja yang tergolong inaktif sebesar 73,0\%, dan 59,5\% remaja sering mengkonsumsi makanan cepat saji (fast foods). Remaja tergolong inaktif beraktivitas fisik yang memiliki komposisi lemak tubuh yang tinggi sebesar 35,2\% ( $p$-value $=0,161 ; \alpha>0,05$ ). Dan persentase remaja yang sering mengkonsumsi fast foods memiliki komposisi lemak tubuh yang tinggi sebesar 36,4\% ( $p$-value = 0,210; $\alpha>0,05)$. Kesimpulan pada penelitian ini yaitu tidak ada hubungan yang bermakna antara aktivitas fisik dan konsumsi makanan cepat saji (fast foods) dengan komposisi lemak tubuh pada remaja.
\end{abstract}

Kata Kunci : Aktivitas fisik, makanan cepat saji, lemak, remaja

\begin{abstract}
Being overweight and obesity in adolescents are risk factors of diabetes, cardiovascular disease and cancer. This happened of accumulation of fat in adipose tissue. This study aims to determine the relationship of physical activity and fast foods consumption with the composition of body fat in adolescents in Karuna Dipa High School Palu. This is the analytic research using a cross sectional approach. The population in this study amounted to 159 people. Sample of this study consisted of 74 people taken by using systematic random sampling technique. Data of body fat composition is known through measurements using KERN's Bioelectrical Impedance Analysis (BIA) tool, physical activity data is obtained using by physical activity questionnaires of a week ago, and data of fast foods consumption last month was obtained by using FFQ form (Food Frequency Questionnaire). Data analysis using chi square test with $\alpha$ value of $\alpha=0.05$. The results showed $29.7 \%$ of adolescents had a high body fat composition. The percentage of adolescents classified as inactive is $73.0 \%$, and $59.5 \%$ of adolescents often consume fast foods. Adolescents are classified as inactive with physical activity which has a high body fat composition of $35.2 \%$ ( $p$-value $=0.161 ; \alpha>0.05$ ). And the percentage of adolescents who often consume fast foods has a high body fat composition of 36.4\% ( $p$-value $=0.210 ; \alpha>0.05$ ). The conclusion of this study is there is no meaningful relationship between physical activity and consumption of fast foods with the body fat composition in adolescents.
\end{abstract}

Keywords : Physical activity, fast food, fat, teenagers

\author{
Sekretariat \\ Editorial: Kampus FKM UNISMUH PALU - Palu 94118, \\ Sulawesi Tengah, Indonesia \\ Telp/HP: +6281245936241, Fax (0451) 425627 \\ E-mail: jurnal.mppki@gmail.com \\ OJS: http://jurnal.unismuhpalu.ac.id/index.php/PJKM
}

\author{
Article History: \\ $\Rightarrow \quad$ Received 02 September 2018 \\ $\Rightarrow \quad$ Revised 03 Oktober 2018 \\ $\Rightarrow \quad$ Accepted 20 November 2018 \\ $\Rightarrow \quad$ Available online 31 Desember 2018
}




\section{PENDAHULUAN}

Dalam meningkatkan kualitas sumber daya manusia (SDM), pembangunan kesehatan dilakukan dengan tujuan untuk meningkatkan kualitas sumber daya manusia. Salah satu peran yang cukup signifikan dalam peningkatan kualitas SDM adalah gizi yang baik, terutama peningkatan status gizi pada remaja. Masalah gizi pada remaja muncul diiringi dengan perilaku gizi yang salah. Hal ini ditandai dengan ketidakseimbangan antara asupan energi dengan keluaran energi. Asupan energi tinggi bila konsumsi makanan berlebihan, sedangkan keluaran energi akan rendah bila metabolisme tubuh dan aktivitas fisik rendah (Adriani \& Wirjatmadi, 2012).

Kelompok remaja merupakan kelompok yang rentan mengalami masalah berat badan lebih yang diakibatkan peningkatan timbunan lemak yang berlebihan. Pada masa remaja, tubuh mengalami perubahan komposisi tubuh yakni penimbunan lemak yang sangat pesat selama masa growth spurt. Penimbunan lemak tubuh terjadi hingga mencapai $15-19 \%$ pada masa anak-anak dan sekitar $20 \%$ penimbunan lemak terjadi pada masa remaja (Adriani \& Wirjatmadi, 2012).

Gizi lebih merupakan masalah global yang telah mendunia. Sebuah studi yang dipimpin oleh WHO (World Health Organization) dan Imperial College London 2017, data global pada tahun 2016 untuk kasus obesitas pada anak mencapai angka $50 \mathrm{mi}-$ lyar pada anak perempuan dan 74 milyar pada anak laki-laki. Studi tersebut menunjukkan bahwa jumlah anak obesitas dan remaja (usia 5-19 tahun) di seluruh dunia telah meningkat sepuluh kali lipat dalam empat dekade terakhir. Jika tren saat ini berlanjut, lebih banyak anak dan remaja mengalami obesitas pada tahun 2020. Kasus obesitas pada anak-anak dan remaja meningkat pula pada negara dengan pendapatan rendah dan menengah, terutama di Asia.

Indonesia juga merupakan salah satu negara yang berada di kawasan Asia dengan masalah gizi pada remaja yang cukup tinggi. Berdasarkan data Riskesdas 2013, prevalensi gizi lebih pada remaja usia 13-15 tahun di Indonesia yaitu sekitar $10.8 \%$ yang terdiri dari $8.3 \%$ gemuk dan $2.5 \%$ obesitas, sedangkan pada usia 16-18 tahun mengalami peningkatan yang luar biasa dari 1.4\% (2010) menjadi 7.3\% (2013) yang terdiri dari 5.7\% gemuk dan $1.6 \%$ obesitas. Sementara untuk prevalensi Sulawesi Tengah, hasil Riskesdas tahun 2013 menyebutkan bahwa prevalensi gizi lebih pada kelompok usia 13-15 tahun sebesar $9.2 \%$ terdiri dari $7.2 \%$ gemuk dan $2.0 \%$ obesitas dan untuk kelompok usia 16-18 tahun juga terjadi lonjakan prevalensi gizi lebih dari 1.3\% (2010) menjadi 6.7\% yang terdiri dari $5.7 \%$ gemuk dan $1.0 \%$ obesitas (Kemenkes RI, 2013).

Penimbunan lemak di dalam tubuh akan meningkatkan seseorang mengalami kelebihan berat badan (overweight) dan mengalami obesitas. Gizi lebih di Indonesia umumnya terjadi di kota-kota besar yang merupakan akibat adanya dampak negatif dari modernisasi seperti perubahan gaya hidup di masyarakat dari traditional life style menjadi sedentary life style (aktivitas fisik yang rendah). Banyak perbedaan yang terjadi antara remaja sekarang dan remaja pada saat dulu. Zaman sekarang anak dan remaja cenderung menghabiskan waktu dengan beraktivitas ringan, seperti menonton televisi, duduk menggunakan sosial media hingga berjamjam, bermain video game, dan sibuk dengan handphone ataupun gadget yang lainnya. Sedangkan remaja pada saat dulu lebih banyak menghabiskan waktu di luar rumah dengan berinteraksi bersama teman sebayanya dan bermain. Aktivitas yang rendah pada kelompok remaja akan meningkatkan risiko gizi lebih karena pengeluaran energi sangat sedikit dan akan menyebabkan penimbunan lemak pada jaringan adiposa (Adriani \& Wirjatmadi, 2012).

Penelitian yang dilakukan oleh Ranggadwipa pada tahun 2014 di Universitas Diponegoro menunjukkan hasil bahwa adanya hubungan yang signifikan antara aktivitas fisik terhadap massa lemak tubuh pada mahasiswa Fakultas Kedokteran Universitas Diponegoro.

Selain dari aktivitas fisik, konsumsi makanan cepat saji juga dapat mempengaruhi seorang remaja dapat mengalami gizi lebih. Banyak dari kelompok remaja cenderung menyukai makanan yang rendah akan kandungan gizi dan memilih makanan cepat saji (fast foods). Ini merupakan penyimpangan konsumsi makanan yang nantinya akan 
mengakibatkan kurangnya nafsu makan remaja terhadap makanan yang sehat dan bergizi. Fast foods merupakan kultur remaja di perkotaan dan merupakan jenis makanan yang tidak mengandung kandungan gizi yang tidak seimbang. Terkadang makanan siap saji ini banyak mengandung lemak jenuh yang dapat meningkatkan kolesterol dalam darah dan membuat berat badan berlebih (Wiarto, 2013).

Apabila fast foods dikonsumsi secara berlebihan, akan meningkatkan risiko gizi lebih pada remaja. Hal ini ditunjukkan pada penelitian yang dilakukan oleh Wahyuni (2013), menunjukkan bahwa terdapat hubungan yang signifikan antara konsumsi fast foods dengan kejadiaan obesitas pada remaja di Akademik Kebidanan Muhammadiyah Banda Aceh. Gaya hidup di perkotaan yang meliputi rendahnya aktivitas fisik, meningkatnya aktivitas kurang gerak (sedentary behavior), makanan yang tidak sehat seperti tinggi lemak jenuh, gula dan makanan olahan merupakan penyebab kemungkinan munculnya epidemi obesitas di negara berkembang (Nasution, 2017).

Kelebihan berat badan (overweight) dan obesitas pada remaja perlu mendapat perhatian khusus, hal ini disebabkan karena overweight dan obesitas merupakan faktor risiko kejadian penyakit kronis, seperti diabetes, penyakit kardiovaskular, dan kanker (WHO, 2017).

SMA Karuna Dipa Kota Palu merupakan salah satu Sekolah Menengah Atas yang terdapat di Kota Palu yang memiliki siswa sebanyak 159 orang, terdiri dari 71 orang siswa perempuan dan 88 orang siswa lakilaki. Hasil studi pendahuluan dan observasi awal penulis yang telah dilakukan pada tanggal 16 Desember 2017, diketahui 6 dari 10 remaja yang diukur mengalami obesitas diketahui melalui pengukuran IMT/U dan observasi secara fisik remaja tersebut dipastikan memiliki komposisi lemak tubuh yang tinggi karena penumpukkan lemak terdapat di bagian perut (SMA Karuna Dipa, 2017).

Berdasarkan uraian di atas, penulis tertarik untuk meneliti mengenai hubungan aktivitas fisik dan konsumsi makanan cepat saji (fast foods) dengan komposisi lemak tubuh dengan menggunakan sampel remaja di SMA Karuna Dipa Kota Palu.

\section{BAHAN DAN METODE}

Penelitian ini merupakan jenis penelitian analitik dengan menggunakan pendekatan cross sectional. Penelitian ini dilaksanakan di SMA Karuna Dipa Kota Palu yang dilaksanakan pada bulan FebruariMaret 2018 dengan pengumpulan data dilakukan secara bertahap. Populasi pada penelitian ini berjumlah 159 orang. Sampel pada penelitan ini berjumlah 74 orang dengan teknik pengambilan sampel menggunakan systematic random sampling. Pengumpulan data aktivitas fisik menggunakan kuesioner aktifitas fisik yang mencantumkan daftar aktifitas fisik, responden dikatakan dikatakan aktif apabila berpartisipasi dalam aktivitas berat paling sedikit 3 kali seminggu untuk minimal 20 menit tiap sesi atau berpartisipasi dalam aktivitas sedang paling sedikit 3 jam dan sedikitnya 5 sesi dalam 1 minggu. Dan responden dikategorikan inaktif apabila tidak memenuhi syarat.

Data konsumsi makanan cepat saji (fast foods) menggunakan formulir FFQ (Food Frequency Questionnaire). Responden dikatakan sering mengkonsumsi makanan cepat saji (fast foods) apabila mengkonsumsi salah satu makanan cepat saji (fast foods) $\geq 3 \mathrm{x} /$ minggu dan dikatakan jarang apabila responden mengkonsumsi $<3 \mathrm{x} /$ minggu. Sedangkan data komposisi lemak tubuh didapatkan melalui pengukuran lemak tubuh menggunakan alat BIA (Bioelectrical Impedance Analysis) dengan kategori memiliki komposisi lemak tubuh yang tinggi jika pada hasil pengukuran persen lemak tubuh untuk perempuan $>33 \%$ dan $>25 \%$ untuk laki-laki. Responden dikatakan memiliki komposisi lemak tubuh yang normal jika pada hasil pengukuran untuk perempuan $\leq 33 \%$ dan $\leq 25 \%$ untuk laki-laki. Analisis data pada penelitian ini menggunakan uji chi-squre dengan nilai $\alpha=0,05$ dan penyajian data disajikan dalam bentuk tabel distribusi frekuensi disertai dengan penjelasan tabel berupa narasi.

\section{HASIL}

1. Karakteristik Subjek Penelitian

Karakteristik subjek penelitian terdiri dari siswa kelas X, XI, dan XII. Jumlah subjek pada penelitian ini didominasi oleh kelas XII dengan persentase sebesar 43,0\% 
(32 orang). Persentase umur responden didominasi oleh umur 17 tahun yaitu sebesar 41,9\% (31 orang) dan umur 15 tahun sebesar $25,7 \%$ (19 orang). Subjek penelitian didominasi oleh jenis kelamin laki-laki dengan persentase sebesar 55,4\% (41 orang). Dan sebesar 8,1\% (6 orang) responden menyatakan bahwa orang tuanya memiliki riwayat obesitas.

\section{Analisis Univariat}

Data aktifitas fisik menunjukkan bahwa terdapat 20 responden $(27,0 \%)$ tergolong aktif dan 54 responden $(73,0 \%)$ tergolong inaktif. Data konsumsi makanan cepat saji (fast foods) didapatkan bahwa 44 responden $(59,5 \%)$ sering mengkonsumsi makanan cepat saji (fast foods) dan 30 responden $(40,5 \%)$ jarang mengkonsumsi makanan cepat saji (fast foods). Data komposisi lemak tubuh menunjukkan hasil bahwa terdapat 52 responden $(70,3 \%)$ memiliki komposisi lemak tubuh normal dan 22 responden $(29,7 \%)$ memiliki komposisi lemak tubuh tinggi.

\section{Analisis Bivariat}

Dari hasil analisis bivariat terdapat 17 responden $(85,0 \%)$ memiliki komposisi lemak tubuh yang normal dan 3 responden $(15,0 \%)$ memiliki komposisi lemak tubuh yang tinggi dengan kategori aktif beraktivitas fisik. Sementara untuk responden dalam kategori inaktif, terdapat 35 responden $(64,8 \%)$ memiliki lemak tubuh yang normal dan 19 responden $(35,2 \%)$ memiliki lemak tubuh yang tinggi. Hasil dari uji statistik didapatkan nilai $p$-value $=0,161 ; a>0,05$. Hal ini menunjukkan bahwa tidak adanya hubungan yang bermakna antara aktivitas fisik dengan komposisi lemak tubuh.

Pada data konsumsi makanan cepat saji (fast foods) didapatkan hasil bahwa terdapat 28 responden $(80,0 \%)$ memiliki komposisi lemak tubuh yang normal dan 16 responden $(36,4 \%)$ memiliki komposisi lemak tubuh yang tinggi dengan kategori sering mengkonsumsi makanan cepat saji (fast foods). Sementara untuk responden dalam kategori jarang mengkonsumsi makanan cepat saji (fast foods), terdapat 24 responden $(80,0 \%)$ memiliki lemak tubuh yang normal dan 6 responden $(20,2 \%)$ memiliki lemak tubuh yang tinggi. Hasil dari uji statistik didapatkan nilai $p$-value $=p$-value $=0,210$; $a>0,05$. Hal ini menunjukkan bahwa tidak adanya hubungan yang bermakna antara konsumsi makanan cepat saji (fast foods) dengan komposisi lemak tubuh.

\section{PEMBAHASAN}

1. Hubungan Aktivitas Fisik dengan Komposisi Lemak Tubuh Pada Remaja

Pada penelitian ini tidak terdapat hubungan yang bermakna antara aktivitas fisik dengan komposisi lemak tubuh pada remaja. Berbeda dengan hasil penelitian yang dilakukan oleh Ranggadwipa (2014) pada mahasiswa di Universitas Diponegoro, bahwa terdapat hubungan yang bermakna antara aktivitas fisik terhadap massa lemak tubuh. Hasil tersebut menyebutkan adanya korelasi negatif antara aktivitas fisik terhadap massa lemak tubuh responden. Korelasi negatif mengartikan bahwa semakin tinggi aktivitas fisik maka massa lemak tubuh akan semakin rendah. Penelitian serupa yang dilakukan oleh Adityawarman (2007) pada remaja di SMP Domenico Savio Semarang, menyatakan bahwa aktivitas fisik pada remaja mempunyai hubungan positif dengan lemak tubuh karena mempunyai pengaruh terhadap lemak tubuh dan lingkar pinggang. Dari hasil tersebut dinyatakan bahwa inaktivitas remaja menyebabkan meningkatnya persen lemak tubuh.

Menurut asumsi peneliti, tidak adanya hubungan antara variabel dalam penelitian ini dikarenakan adanya aktivitas yang homogen untuk sebagian besar responden. Aktivitas fisik dengan kategori inaktif lebih mendominasi untuk sebagian besar responden, sehingga menyebabkan tidak adanya keterkaitan antara aktivitas fisik dengan komposisi lemak tubuh pada remaja. Walaupun dalam penelitian ini tidak terdapat hubungan antara aktivitas fisik dengan komposisi lemak tubuh, tetapi data penelitian ini menunjukkan bahwa remaja yang tergolong inaktif mempunyai kecenderungan 2,35x untuk memiliki komposisi lemak tubuh yang tinggi dibandingkan dengan remaja yang aktif beraktivitas fisik. Hal ini sesuai dengan teori yang dinyatakan oleh Adriani \& Wirjatmadi (2012) bahwa aktivitas yang rendah pada kelompok remaja akan meningkatkan risiko gizi lebih karena rendahnya pengeluaran energi dan akan menyebabkan penimbunan lemak pada jaringan adiposa. 
2. Hubungan Konsumsi Makanan Cepat Saji (Fast Foods) dengan Komposisi Lemak Tubuh Pada Remaja

Pada penelitian ini tidak terdapat hubungan yang bermakna antara konsumsi makanan cepat saji (fast foods) dengan komposisi lemak tubuh pada remaja. Hasil penelitian ini mendukung penelitian sebelumnya yang dilakukan oleh Heriyanto (2012) yang menyatakan bahwa tidak ada hubungan antara konsumsi fast foods dengan persen lemak tubuh pada remaja perempuan. Penelitian yang dilakukan oleh Heriyanto (2012) menggunakan alat BIA (Bioelectrical Impedance Analysis) untuk menentukan persen lemak tubuh. Penelitian yang serupa juga dilakukan oleh Bayuningsih (2015) yang menyatakan bahwa tidak ada keterkaitan antara frekuensi konsumsi dengan tebal lemak bawah kulit pada remaja perempuan. Pada penelitian tesebut sekitar $54,5 \%$ remaja tergolong sering mengkonsumsi fast foods $\geq 8 \mathrm{x} /$ minggu. Jenis fast foods yang dikonsumsi terdiri dari fast foods modern yang tersedia di restoran fast foods dan fast foods lokal yang dijual di pedagang kaki lima. Penelitian yang dilakukan oleh Bayuningsih (2015) tersebut menggunakan alat skinfold caliper untuk mengetahui tebal lemak bawah kulit.

Tidak adanya hubungan yang bermakna antara konsumsi makanan cepat saji (fast foods) dengan komposisi lemak tubuh pada penelitian ini bisa disebabkan karena konsumsi makanan cepat saji hanya melihat frekuensi konsumsi fast foods tanpa menghitung besar porsi yang dikonsumsi oleh responden. Oleh karena itu, tidak dapat ditemukan hubungan yang bermakna antara konsumsi makanan cepat saji (fast foods) dengan komposisi lemak tubuh.

Walaupun pada penelitian ini tidak terdapatnya hubungan yang bermakna antara konsumsi fast foods dengan komposisi lemak tubuh pada remaja, namun dari data penelitian ini menunjukkan bahwa remaja dengan kategori sering mengkonsumsi fast foods memiliki kecenderungan 1,8x untuk memiliki komposisi lemak tubuh tinggi. Penelitian yang dilakukan oleh Wahyuni (2013) pada remaja di Akademia Kebidanan Muhammadiyah Banda Aceh menyatakan bahwa terdapat hubungan yang bermakna antara konsumsi fast foods dengan kejadian obesitas dengan hasil uji statistik $\mathrm{P}=0,000$. Pada hasil penelitian tersebut menyatakan bahwa proporsi obesitas lebih tinggi pada remaja yang sering mengkonsumsi fast foods dibandingkan dengan remaja yang jarang mengkonsumsi fast foods. Hal ini sesuai dengan teori yang menyatakan bahwa fast foods memiliki kandungan yang tinggi energi, lemak, garam (natrium), dan rendah serat sehingga dapat menyebabkan permasalahan kesehatan yakni gizi lebih.

\section{KESIMPULAN DAN SARAN}

Pada penelitian ini menunjukkan hasil bahwa tidak ada hubungan antara aktivitas fisik dengan komposisi lemak tubuh pada remaja di SMA Karuna Dipa Palu dan tidak ada hubungan antara konsumsi makanan cepat saji (fast foods) dengan komposisi lemak tubuh pada remaja di SMA Karuna Dipa Palu.

Pada penelitian ini disarankan agar remaja SMA Karuna Dipa agar meningkatkan aktivitas fisik serta mengurangi konsumsi jajanan fast foods. disarankan untuk peneliti selanjutnya agar dapat menggunakan metode yang lebih akurat untuk mengetahui aktivitas fisik serta memasukkan kuantitas atau besaran porsi fast foods yang dikonsumsi oleh responden.

\section{DAFTAR PUSTAKA}

Adityawarman. 2007. Hubungan Aktivitas Fisik Dengan Komposisi Tubuh pada Remaja. Artikel penelitian: Fakultas Kedokteran Universitas Diponegoro (Online) (http:// eprints.undip.ac.id/22215/1/ Aditya.pdf) diakses 19 Desember 2017)

Adriani, M.\& Wirjatmadi B. 2012. Pengantar Gizi Masyarakat. Kencana Prenada Media Group: Jakarta.

Adriani, M.\& Wirjatmadi B. 2012. Peranan Gizi dalam Siklus Kehidupan. Kencana Prenada Media: Jakarta.

American Diabetes Association. 2015. Physical Activity is Important. (http:// www.diabetes.org/food-and-fitness/ fitness/physical-activity-isimportant.html) diakses tanggal 15 Desember 2017.

Bayuningsih, N. S. 2015. Hubungan Antara Frekuensi Konsumsi Fast Food Dan Ak- 
tivitas Fisik Dengan Tebal Lemak Bawah Kulit Siswi Sma N 6 Yogyakarta (online), (http:// eprints.ums.ac.id/39842/9/NASKAH\% 20PUBLIKASI_\%20J310131002.pdf) diakses 22 Juli 2018

Heriyanto, Mira H. 2012. Hubungan Asupan Gizi dan Faktor Lain dengan Persen Lemak Tubuh pada Mahasiswa Prodi Gizi dan Ilmu Komunikasi UI Angkatan 2009 Tahun 2012. Skripsi. Fakultas Kesehatan Masyarakat: Universitas Indonesia.

Kementerian Kesehatan RI. 2013. Riset Kesehatan Dasar (Riskesdas) 2013. Jakarta.

Ranggadwipa, D. D. 2014. Hubungan Aktivitas Fisik Dan Asupan Energi Terhadap Massa Lemak Tubuh Dan Lingkar Pinggang Pada Mahasiswa Fakultas Kedokteran Universitas Diponegoro. (online), (ejournal3.undip.ac.id/index.php/ medico/article/ download/7637/7397) diakses 22 Juli 2018

Wahyuni, S. 2013. Hubungan Konsumsi Fast Food Dengan Obesitas Pada Remaja di Akademi Kebidanan Muhammadiyah Banda Aceh. Skripsi. Sekolah Tinggi Ilmu Kesehatan U'Budiyah: Banda Aceh.

Wahyuningsih, R. 2013. Penatalaksanaan Diet Pada Pasien. Graha Ilmu: Yogyakarta.

[WHO] World Health Organizaton, 2017. Tendfold increase in childhood and adolescents obesity in four decades: new study by Imperial Collage London and WHO. (Online) (http://www.who.int/ mediacentre/news/releases/2017/ increase-childhood-obesity/en) diakses tanggal 18 Desember 2017.

Wiarto, G. 2013. Ilmu Gizi Dalam Olahraga. Gosyen Publishing: Yogyakarta 


\section{LAMPIRAN}

Tabel 1. Distribusi Karakteristik Remaja di SMA Karuna Dipa Palu

\begin{tabular}{|c|c|c|}
\hline & \multicolumn{2}{|c|}{$\begin{array}{c}\begin{array}{c}\text { Karakteristik Responden } \\
n=74\end{array} \\
\end{array}$} \\
\hline & (n) & (\%) \\
\hline \multicolumn{3}{|l|}{ Kelompok Kelas } \\
\hline 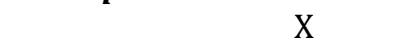 & 22 & 29,7 \\
\hline XI & 20 & 27,0 \\
\hline XII & 32 & 43,2 \\
\hline \multicolumn{3}{|l|}{ Kelompok Umur (Thn) } \\
\hline 14 & 1 & 1,4 \\
\hline 15 & 19 & 25,7 \\
\hline 16 & 17 & 23,0 \\
\hline 17 & 31 & 41,9 \\
\hline 18 & 6 & 8,1 \\
\hline \multicolumn{3}{|l|}{ Jenis Kelamin } \\
\hline Laki-laki & 41 & 55,4 \\
\hline Perempuan & 33 & 44,6 \\
\hline \multicolumn{3}{|c|}{ Riwayat Obesitas Orang Tua } \\
\hline Ada & 6 & 8,1 \\
\hline Tidak Ada & 68 & 91,9 \\
\hline
\end{tabular}

Sumber: Data Primer Terolah, 2018

Tabel 2. Distribusi Aktivitas Fisik Remaja di SMA Karuna Dipa Palu

\begin{tabular}{cll}
\hline Aktivitas Fisik & n & \% \\
\hline Aktif & 20 & 27,0 \\
Inaktif & 54 & 73,0 \\
\hline Total & 74 & 100,0 \\
\hline
\end{tabular}

Sumber: Data Primer Terolah, 2018

Tabel 3. Distribusi Konsumsi Makanan Cepat Saji (Fast Foods) Remaja di SMA Karuna Dipa Palu

\begin{tabular}{ccl}
\hline $\begin{array}{c}\text { Konsumsi Makanan Cepat } \\
\text { Saji (Fast Foods) }\end{array}$ & n & \% \\
\hline Sering & 44 & 59,5 \\
Jarang & 30 & 40,5 \\
\hline Total & $\mathbf{7 4}$ & $\mathbf{1 0 0 , 0}$ \\
\hline
\end{tabular}

Sumber: Data Primer Terolah, 2018 
Tabel 4. Distribusi Komposisi Lemak Tubuh Remaja di SMA Karuna Dipa Palu

\begin{tabular}{cll}
\hline Komposisi Lemak Tubuh & $\mathbf{n}$ & \% \\
\hline Normal & 52 & 70,3 \\
Tinggi & 22 & 29,7 \\
\hline Total & 74 & 100,0 \\
\hline
\end{tabular}

Sumber: Data Primer Terolah, 2018

Tabel 5. Hubungan Aktivitas Fisik dengan Komposisi Lemak Tubuh Pada Remaja di SMA Karuna Dipa Palu

\begin{tabular}{|c|c|c|c|c|c|c|c|}
\hline \multirow{3}{*}{ Aktivitas Fisik } & \multicolumn{4}{|c|}{ Komposisi Lemak Tubuh } & \multirow{2}{*}{\multicolumn{2}{|c|}{ Total }} & \multirow{3}{*}{ P Value } \\
\hline & \multicolumn{2}{|c|}{ Normal } & \multicolumn{2}{|c|}{ Tinggi } & & & \\
\hline & $\mathbf{n}$ & $\%$ & $\mathbf{n}$ & $\%$ & $\mathbf{n}$ & $\%$ & \\
\hline Aktif & 17 & 85,0 & 3 & 15,0 & 19 & 100 & \\
\hline Inaktif & 35 & 64,8 & 19 & 35,2 & 55 & 100 & 0,161 \\
\hline
\end{tabular}

Sumber: Data Primer Terolah, 2018

Tabel 6. Hubungan Konsumsi Makanan Cepat Saji (Fast Foods) dengan Komposisi Lemak Tubuh Pada Remaja di SMA Karuna Dipa Palu

\begin{tabular}{|c|c|c|c|c|c|c|c|}
\hline \multirow{3}{*}{$\begin{array}{c}\text { Konsumsi Ma- } \\
\text { kanan Cepat } \\
\text { Saji (Fast } \\
\text { Foods) }\end{array}$} & \multicolumn{4}{|c|}{ Komposisi Lemak Tubuh } & \multirow{2}{*}{\multicolumn{2}{|c|}{ Total }} & \multirow{3}{*}{ P Value } \\
\hline & \multicolumn{2}{|c|}{ Normal } & \multicolumn{2}{|c|}{ Tinggi } & & & \\
\hline & $\mathbf{n}$ & $\%$ & $\mathbf{n}$ & $\%$ & $\mathbf{n}$ & $\%$ & \\
\hline Sering & 28 & 63,6 & 16 & 36,4 & 44 & 100 & \\
\hline Jarang & 24 & 80,0 & 6 & 20,2 & 30 & 100 & 0,210 \\
\hline
\end{tabular}

Sumber: Data Primer Terolah, 2018 